\title{
LA DISTRIBUCIÓN DEL RIESGO Y LA BUENA FE. A PROPÓSITO DEL ERROR, EL DOLO Y LOS DEBERES PRECONTRACTUALES DE INFORMACIÓN
}

["Risk Distribution and Good Faith. On the Error, Fraud and pre-contractual Duties of Disclosure"]

\author{
IÑIgo de LA MAZa GAZMURI* \\ Universidad Diego Portales, Santiago, Chile
}

\begin{abstract}
RESUMEN
Abstract

Además de los deberes precontractuales de información consagrados explícitamente en el ordenamiento jurídico, el principio general de buena fe permite al juez extraer otros que pueden ser denominados "atípicos". Dichos deberes carecen de regulación; por lo mismo, deben incardinarse en la disciplina de otras figuras. El trabajo se ocupa de dos de esas figuras: el error y el dolo. Se sostiene que al poner en relación los deberes precontractuales de información, el error y el dolo, no solamente se logra una mejor comprensión de estas dos últimas figuras, sino que es posible advertir con mayor precisión cómo funciona el principio general de la buena fe.

Palabras clave

Contratos - Error - Dolo - Buena fe.

Besides the pre-contractual duties of disclosure explicitly included in the legal system, the general principle of good faith allows the judge to infer other principles that can be called "atypical". Said duties lack regulation; therefore, they must be incorporated in the discipline of other constructs. This article focuses on two of those concepts: error and fraud. We hold that when relating pre-contractual duties of disclosure, error and fraud, not only a better understanding of these concepts is obtained, but also it is possible to notice, in a more accurately manner, how the good faith principle works.

$$
\begin{gathered}
\text { KEYwORDS } \\
\text { Contracts - Error - Fraud - Good }
\end{gathered}
$$
faith.

[Recibido el 31 de julio y aCePTADo el 30 de agosto de 2011].

* Doctor en Derecho, profesor de Derecho Civil e investigador en la Facultad de Derecho de la Universidad Diego Portales. Dirección postal: República 105, Santiago, Chile. Correo electrónico: inigo.delamaza@udp.cl. Este artículo se enmarca en el Proyecto FONDECYT regular № 1100029, sobre los deberes precontractuales de información en el derecho chileno.
\end{abstract}




\section{INTRODUCCIÓN ${ }^{1}$}

En otro trabajo he sugerido que la distinción entre deberes precontractuales de información típicos $(=$ dpit.) y deberes precontractuales de información atípicos ( $=$ dpia.) constituye un dispositivo que contribuye a aligerar la complejidad del estudio de los deberes precontractuales de información (= dpi.) $)^{2}$.

En las páginas que siguen me interesa prestar atención, especialmente, a una peculiaridad de los dpia.: la incardinación.

Lo característico de los dpia. es que carecen de una regulación autónoma, por lo mismo, cuando un contratante estima que no se le ha suministrado información que la otra parte debió proporcionarle, debe canalizar su pretensión (indemnizatoria, resolutoria, anulatoria o la que sea) a través de una figura que posea su propia regulación. Es a esto a lo que denomino incardinación.

Desde mi punto de vista, es posible que dicha incardinación se produzca en las figuras del error vicio del consentimiento ${ }^{3}$, del dolo in contrahendo ${ }^{4}$, en los remedios del incumplimiento contractual o, directamente, a través de las reglas del Derecho de daños. Para efectos de este trabajo, sin embargo, voy a limitarme a las figuras del error y el dolo. Desde luego, la extensión de un trabajo como éste aconseja liberarse de la tentación de tratar todas las posibles formas de incardinación. Por otra parte, la opción por el error y el dolo se justifica, en mi opinión, por el escasísimo desarrollo dogmático que han recibido en Chile.

Este trabajo consta de dos partes. En la primera desarrollo la idea de incardinación. En la segunda muestro con algún detalle cómo sucede este fenómeno tratándose del error y el dolo.

Al terminar este recorrido espero mostrar dos puntos que resultan extremadamente interesantes para quien se interese en el Derecho de contratos. El primero de ellos es que, cuando se presta suficiente atención al error y el dolo se aprende que no se trata, exactamente, de dispositivos orientados

${ }^{1}$ Casi como lema de este trabajo, podrían citarse las palabras de CASTRo y Bravo, Federico, De nuevo sobre el error en el consentimiento, en Anuario de Derecho Civil, 41 (1988) 2, p. 413: ¿Quién merece protección, respecto de su propio error? ¿A quién le estará permitido aprovecharse del error ajeno?

${ }^{2}$ De la Maza Gazmuri, Ínigo, Tipicidad y atipicidad de los deberes precontractuales de información, en Revista de Derecho de la Universidad Católica de Valparaíso, 34 (2010), pp. 75-99.

${ }^{3}$ Me limito aquí al error vicio en los contratos. Salvo que indique otra cosa, me referiré a él simplemente como "error".

${ }^{4}$ Limito mi tratamiento al dolo in contrabendo en los contratos, al cual, salvo que lo indique de otra manera denominaré simplemente "dolo". 
hacia la protección del consentimiento, sino más bien de mecanismos para distribuir el riesgo de la información defectuosa durante la negociación del contrato. El segundo punto es que, en ocasiones, el principio general de la buena fe opera como un instrumento de ponderación de los diversos intereses que subyacen al Derecho de contratos.

\section{INCARDINACIÓN}

\section{Tipicidad y atipicidad de los dpi.}

Mi sugerencia es la siguiente: cuando se presta suficiente atención a la forma en que se concretan los dpi. en el ordenamiento jurídico se advierten dos modalidades diversas: dpit. y dpia. ${ }^{5}$

Existe un dpit. cada vez que el legislador identifica explícitamente el deber o bien, en forma levemente más oblicua, sanciona la falta de entrega de la información durante el período que antecede a la celebración del contrato. Existe, en cambio, un dpia. en todas aquellas ocasiones en las que, sin establecer explícitamente el deber o fijar su sanción, el legislador provee al juez de herramientas suficientes para determinar si, en el caso concreto, existe o no un deber de informar.

Como de costumbre, los ejemplos deberían contribuir. En primer lugar, tratándose de los dpit., como ya ha quedado dicho, pueden existir dos modalidades: aquellos supuestos en los que el legislador establece directamente el deber y aquellos en que sanciona su incumplimiento. En lo que se refiere al primer supuesto, la Ley $\mathrm{N}^{\circ} 19.496$ sobre protección de los derechos de los consumidores es pródiga en ejemplos ${ }^{6}$. Así, por ejemplo, su artículo 3 b) -su norma general en lo que se refiere a dpi.- considera como uno de los derechos del consumidor: "a una información veraz y oportuna sobre los bienes y servicios ofrecidos, su precio, condiciones de contratación y otras características relevantes de los mismos". O bien, su artículo 14 exige al proveedor informar al proveedor acerca del hecho de que los productos que expende adolecen de alguna deficiencia, son usados o refaccionados. En el mismo sentido, el inciso segundo del artículo 30 exige al proveedor informar el precio "de un modo claramente visible que permita al consumidor, de manera efectiva, el ejercicio de sus derecho a elección". Por su parte, el artículo 35 de la ley prescribe: "En toda promoción u oferta se deberá informar al consumidor sobre las bases de la misma y el tiempo o plazo de suduración". Finalmente, el artículo establece un

${ }^{5}$ Aquí me apoyo decididamente en DE la Maza Gazmuri, Í., cit. (n 2).

${ }^{6} \mathrm{He}$ revisado el tema en DE LA MAZA GAZMURI, Íñigo, El suministro de información como técnica de protección de los consumidores: los deberes precontractuales de información, Revista de Derecho de la Universidad Católica del Norte, 17 (Coquimbo, 2010) 2, pp. 21-52. 
extenso catálogo de información que el proveedor debe poner a disposición del consumidor en las operaciones de consumo cuyo objeto sea la concesión de un crédito al primero.

En el segundo supuesto de dpit. no existe, como ya ha quedado dicho, una imposición directa del deber, sino que se sanciona la falta de entrega de información. Un magnífico ejemplo de este último supuesto se encuentra en el tratamiento de los vicios redhibitorios en el Código Civil, particularmente en su artículo $1861^{7}$, según el cual si el vendedor conocía los vicios y no los declaró, o si debía conocerlos, debe indemnizar los daños y perjuicios que esto cause al comprador. La razón por la cual se indemniza no es la presencia de los vicios redhibitorios, las consecuencias aparejadas directamente a estos funcionan objetivamente. Se indemniza porque la conducta del vendedor es reprochable, ya sea porque actuó dolosamente (conocía los vicios y no los comunicó) o bien porque actuó culpablemente (ignoraba la existencia de los vicios pero debió haberla conocido) ${ }^{8}$.

En lo que toca a los dpia. resulta útil como ilustración la sentencia de la Corte Suprema de 19 de mayo de $2008^{9}$. Se trata de un contrato de arrendamiento de un predio con el objeto de dedicarlo a un campo de minigolf. En los hechos, el predio se encontraba sujeto a ciertas limitaciones urbanísticas que impedían dedicarlo al fin proyectado en el contrato. La arrendataria solicita la terminación del contrato y la indemnización de daños y perjuicios por incumplimiento contractual. Conociendo de esta pretensión la Corte de Apelaciones de Santiago llega a la conclusión de que la arrendadora no podía ignorar las limitaciones urbanísticas y al no comunicárselas a la arrendataria durante la negociación del contrato había infringido una de las exigencias

${ }^{7}$ Sobre el tema puede consultarse: de la Maza Gazmuri, Íñigo, A propósito del articulo 1861, en AA.VV., Estudios de Derecho civil, V: Jornadas Nacionales de Derecho Civil, Universidad de Concepción, 2009 (Santiago, Abeledo Perrot, Santiago, 2010), pp. 455-470.

${ }^{8} \mathrm{Al}$ respecto puede revisarse la interesante sentencia de la Corte Suprema de 27 de marzo de 2008, recaída en el caso "Rosario Larzabal Beraza con Sociedad Inmobiliaria Talasia Limitada”, No identificador Legal Publishing 38680, en la cual se lee: “[...] los vicios ocultos pueden dar origen independientemente a las acciones redhibitoria; quanti minoris e indemnizatoria, lo cual guarda concordancia con distintas disposiciones del Código Civil, pero fundamentalmente con la regulación que el mismo Código realiza en relación con la condición resolutoria tácita, que en este caso está reglamentada especialmente. Es por ello que de interponerse ya la acción redhibitoria, ya la quanti minoris, igualmente se puede solicitar la indemnización de perjuicios o, de estimarlo pertinente el comprador, limitar sus pretensiones únicamente a la reparación de los daños".

${ }^{9}$ Caso "Glide Diversiones Limitada con Compañía de Inversiones y Desarrollo Sur S.A.”, No identificador Legal Publishing 39372. Con comentario de DE LA MAZA Gazmuri, Ínigo, en Revista Chilena de Derecho Privado "Fernando Fueyo Laneri", 13 (2009), pp. 249-257. 
que el principio de la buena fe plantea a las partes durante la negociación del contrato. En palabras del Tribunal de Alzada: "La expectativa es que en esta etapa [la precontractual], los contratantesse den toda la información necesaria para definir los términos del contrato y que esté orientada a ilustrar de la mejor forma a la otra parte, en una actitud de corrección y lealtad".

En lo que interesa inmediatamente, lo importante es que la Corte deriva de la buena fe (a eso se refiere con "actitud de corrección y lealtad") un deber precontractual de información para la arrendadora. A diferencia de los ejemplos de dpit., en este caso el legislador no ha dispuesto una norma jurídica de la cual desprender dicho deber, sino que, cosa distinta, es el juez, sirviéndose del principio general de la buena fe quien ha determinado la existencia de dicho deber.

\section{Atipicidad e incardinación.}

El caso que recién he expuesto muestra que los dpia. se derivan directamente de las exigencias de la buena fe. Lo segundo que es posible extraer de él es que, en dicho caso, la infracción del dpia. se canalizó a través de una acción resolutoria. Para decirlo de otra manera, la infracción del deber precontractual de información (no haber señalado la arrendadora la existencia de limitaciones urbanísticas) fue absorbida por la disciplina de un remedio propio del régimen del incumplimiento contractual: la resolución.

Al pensar las cosas de esta manera surgen un par de temas que simplemente dejo planteados aquí. El primero de ellos es que ciertos ilícitos precontractuales, en definitiva, pueden ser alegados ya sea a través de acciones propias de ese período (en este caso podría haber sido el error o, eventualmente, si se considera que la arrendadora conocía la información, el dolo) o bien a través de remedios contractuales ${ }^{10}$. El segundo tema-cercanamente relacionado al primero- es que en la discusión acerca de cuál sea el régimen de responsabilidad propio de los ilícitos precontractuales, probablemente, la distinción más importante sea si llegó a existir contrato o no. En general, cuando existe contrato y la información que debía suministrarse y no se comunicó se relaciona con circunstancias que van a determinar el incumplimiento de la prestación de quien calló la otra parte va a poder optar por acciones propias del periodo precontractual o bien por los remedios del incumplimiento contractual ${ }^{11}$.

${ }^{10}$ Me he ocupado del tema en De la maza Gazmuri, Ínigo, Los límites del deber precontractual de información (Cizur Menor [Navarra], Civitas-Thomson Reuters, 2010), pp. 268-273. Para una sentencia en la cual la infracción de dpi. se incardina en la disciplina del error puede consultarse la n. 33.

${ }^{11}$ En un sentido similar: Rojo AJuria, Luis, El dolo en los contratos (Madrid, Civitas, 1994), pp. 142-147, quien sugiere, con citas de Carrasco y de Morales Moreno, que 
Pues bien, como ha quedado dicho, una manera de incardinar las pretensiones derivadas del incumplimiento de dpia. es a través de los remedios propios del incumplimiento contractual. La segunda es a través del régimen general de responsabilidad extracontractua ${ }^{12}$. A este respecto, Ghestin, por ejemplo, ha señalado que, en el ámbito francés, una de las formas en que los tribunales han reconocido la existencia de un deber de informar ha sido recurriendo al artículo 1382 del Code $e^{13}$. Dicho reconocimiento parece haber operado en dos etapas. La primera de ellas ha sido de forma complementaria a la anulación por dolo o por error ${ }^{14}$. La violación del deber precontractual de informar que acompañaba a supuestos de error o dolo se consideraba como una falta precontractual sancionada sobre el terreno de la responsabilidad extracontractual ${ }^{15}$. Más recientemente, los tribunales han recurrido directamente a la responsabilidad delictual para sancionar infracciones al deber de informar, sin acudir a las figuras del error y el dolo ${ }^{16}$. En el ámbito español las cosas son más o menos semejantes. De una parte, los tribunales han utilizado las normas que disciplinan la responsabilidad extracontractual en casos en los que lo que se reclamaba era la anulación del contrato por error o dolo ${ }^{17}$. De otra parte $-y$ en lo que interesa aquí-, la doctrina ha señalado que algunas manifestaciones de la infracción del deber de informar pueden reclamarse acudiendo únicamente a las reglas del Derecho de daños. Un ejemplo de esto último se encuentra en el deber de informar las causas de nulidad del contrato ${ }^{18}$. Una parte de la

la diferenciación que es posible establecer entre el dolo y el incumplimiento se asemeja a la diferencia entre los términos y las representaciones propias de la "misrepresentation" inglesa (véanse las pp. 252-254). Lo determinante para deslindar las acciones de dolo y de incumplimiento no sería el factor cronológico, sino si, aquello sobre lo cual recayó el engaño, se incorporó o no al contrato.

${ }^{12}$ Sobre lo mismo: De la MAZa Gazmuri, Í., cit. (n. 10).

${ }^{13}$ GHestin, Jacques, Traité de droit civil. Les obligations. La formation du contrat (Paris, LGDJ, 1993), p. 605. Como se sabe, dicho precepto desempeña la misma función que el artículo 2314 CC. en el Derecho chileno y su texto reza: "Tout fait quelconque de lhomme, qui cause à autrui un dommage, oblige celui par la faute duquel il est arrivé, à le réparer".

${ }^{14}$ Ghestin, J., cit. (n. 13), p. 605.

${ }^{15}$ En el derecho francés el régimen de la responsabilidad precontractual es el propio de la responsabilidad extracontractual. Al respecto, véase, por ejemplo: SCHMIDT, Joanna, La sanction de la faute précontractuelle, en Revue Trimestrelle de Droit Civil, 46 (1974), pp. 46-73.

${ }^{16}$ GHestin, J., cit. (n. 13), p. 606, con cita de dos sentencias en este sentido.

${ }^{17}$ Así, respecto del dolo véase: VERDA y BEAmonte, José Ramón, Algunas reflexiones en torno a la excusabilidad y recognoscibilidad del error en los contratos, en Anuario de Derecho Civil, 50 (1997) 3, pp.761-777.

${ }^{18} \mathrm{La}$ doctrina española parece encontrarse de acuerdo en que las exigencias de la buena fe imponen a las partes informarse recíprocamente sobre la existencia de causas 
doctrina estima que aquella de las partes que conociendo, o debiendo conocer, una causa de nulidad no se la informa a la otra parte incurre en responsabilidad precontractual cuyo fundamento se encuentra en el artículo $1902^{19}$. Si esto es correcto significa que, en esas hipótesis, la pretensión indemnizatoria derivada del incumplimiento del deber de informar sobre la existencia de una causa de nulidad del negocio celebrado se canaliza a través de las normas de responsabilidad extracontractual.

de nulidad del contrato. Así, por ejemplo, se ha señalado que en el deber precontractual de informar se comprenden fundamentalmente las causas de nulidad. En este sentido Alonso Pérez, Mariano, La responsabilidad precontractual, en Revista Crítica de Derecho Inmobiliario, 485 (1971), pp. 907-908. Véase también: Asúa GonzÁlez, Clara, La culpa "in contrahendo" (Bilbao, Servicio Editorial Universidad del País Vasco, 1989), p. 262; GARCía Rubio, María Paz, La responsabilidad precontractual (Madrid, Tecnos, 1991), p. 187; Gómez CALle, Esther, Los deberes precontractuales de información (Madrid, La Ley, 1994), pp. 101-116. Por su parte, Verda y BeAmonte, José Ramón, La reticencia en la formación del contrato, en Aranzadi Civil, 22 (1999), p. 12 , señala, en términos más amplios, que: "el principio de la buena fe, durante los tratos preliminares y al tiempo de la conclusión del contrato, impone a las partes contratantes el deber de informarse recíprocamente de la existencia de las causas de invalidez negocial, conocidas o recognoscibles mediante el uso de una regular diligencia". Se trata, por lo demás, de una posición con importantes equivalentes en derecho comparado. Dos son especialmente importantes. Uno, como ya se ha visto, es el artículo 1338 CCItal. El otro es el $₫ 311$ a (2) BGB., después de la reforma de 2001, bajo la rúbrica "Impedimento de la prestación a la conclusión del contrato" dispone que: "El acreedor, a su elección, puede exigir resarcimiento del daño en lugar de la prestación o resarcimiento del daño en el lugar de la prestación o resarcimiento de sus gastos con la extensión determinada en el $\$ 284$. Ello no rige si el deudor no conocía el impedimento de la prestación en el momento de la conclusión del contrato y no debe responder de su desconocimiento. El $₫ 281$ apartado 1, incisos 2 y 3, y apartado 5, se aplica por analogía”. En este precepto se ha llevado a cabo la consagración legal de un deber precontractual de información, sólo si el deudor conocía o debía conocer el deudor el impedimento y no lo informa al acreedor responde de los daños ocasionados. Como señalan EHmann, H. - Sutchet, H., La reforma del BGB. Modernización del derecho alemán de obligaciones (traducción de C. López Díaz y U. Salas de Sánchez, Bogotá, Universidad Externado de Colombia, 2006), p. 59: "Los reformistas [del BGB] querían extender el derecho a la indemnización del artículo 311 a II de manera consciente como derecho de indemnización por daños y perjuicios dependiendo de la culpabilidad, y no como responsabilidad por garantía”.

${ }^{19}$ Sobre esto puede consultarse García Rubio, M. P., cit. (n. 18), pp. 191-192. La autora se refiere a la hipótesis de un contrato con objeto inicialmente imposible o ilícito, sin embargo, advierte (ibíd., p. 187 nota 92) que lo dicho respecto a esa causal de nulidad puede, esencialmente, predicarse de otras causas de nulidad diversas. 


\section{ERROR Y DOLO}

De las figuras a las cuales se puede recurrir para incardinar los dpia. me interesa detenerme con mayor acuciosidad en el error y el dolo. Para examinar la relación entre dpia. y el error y el dolo procederé de la siguiente manera. En primer lugar ofrezco un caso que debería contribuir a ilustrar dicha relación. A continuación procuro determinar si la pretensión de la demandante podría haber sido canalizada a través de la disciplina del dolo o del error. Finalmente, examino por separado el dolo y el error.

\section{El"caso Baldus".}

a) Los hechos. Los hechos del caso son los siguientes: una persona sin especiales conocimientos en la materia vende, en una subasta pública, a un profesional cincuenta fotografías de un prestigioso fotógrafo (Baldus) por un precio unitario de mil francos franceses ${ }^{20}$. Un tiempo después, la misma vendedora ofrece, privadamente, otro lote de fotografías al mismo comprador y por el mismo precio. La vendedora ignora que se trata de fotografías de Baldus y el precio que cobra por ellas no se aproxima, ni remotamente, a su valor de mercado ${ }^{21}$. El comprador, desde luego, conocía la autoría de las fotos.

Una vez que la vendedora se entera del verdadero valor de las fotografías, solicita la anulación del segundo contrato de compraventa por dolo del comprador, consistente en no haberle informado acerca de la autoría de las fotografías. La Corte de Apelaciones de París consideró que la falta de lealtad de la conducta del comprador justificaba la anulación del contrato por dolo. Posteriormente, la Corte de Casación estimó que el comprador no tenía el deber de informar al vendedor de que las fotografías eran de un prestigioso artista, por lo que, desestimó la alegación de dolo.

b) Concurso. En el caso, la demandante canalizó su pretensión a través de la disciplina del dolo -específicamente a través del dolo por omisión- la pregunta que me interesa considerar en lo inmediato es si podría haberse servido del error. Esto supone hacerse cargo de dos cuestiones distintas. La primera de ellas es si resulta posible encajar esta situación en alguno de los supuestos de error vicio que considerar el Código Civil. Si, como yo creo, la

${ }^{20}$ Tomo la narración de los comentarios de Mestre, J. - Fages, B. sobre sentencias judiciales recaídas en materia de obligaciones y contratos especiales, en Revue Trimestrelle de Droit Civil (2000), pp. 566-568. Un análisis del caso en Sefton-Green, Ruth, Duties to Inform versus Party Autonomy: Reversing the Paradigm (from Free Consent to Informed Consent)? A Comparative Account of French and English Law, en Howells, G. - JansSEn, A. - SCHulze, R. (editores), Information Rights and Obligations. A Challenge for Party Autonomy and Transactional Fairness (Ashgate, 2005), p. 182.

${ }^{21} \mathrm{El}$ comprador revendió el primer lote en dos millones de francos. 
respuesta es afirmativa, lo segundo que es necesario resolver es si, satisfechos los requisitos tanto del error como del dolo, la parte puede optar entre ellos para canalizar su pretensión.

En primer lugar entonces: ¿qué tipo de error, si es que alguno, sería éste? Desde mi punto de vista se trataría de un error substancial, es decir de aquel regulado en el inciso primero del artículo 1454 CC. Para que así suceda es necesario justificar que la ignorancia de la vendedora recayó sobre una "cualidad esencial" de las fotografías. Y esta justificación precisa determinar qué debe entenderse por cualidad esencial. Como resulta bien sabido, la determinación de qué cualidades son esenciales en el sentido del artículo 1454 CC. puede realizarse acudiendo a un criterio subjetivo o a uno objetivo. Aunque el tema se ha discutido ${ }^{22}$, actualmente la Corte Suprema ha uniformado sus decisiones al respecto. Así parece desprenderse de la importante sentencia de dicho Tribunal de fecha 19 de enero de $2010^{23}$ en la cual, sin ambigüedades y con cita a las ideas de Avelino León Hurtado, opta por un sistema de carácter objetivo, señalando que: "la calidad esencial deberá fijarla en último término el juez, atendiendo a las circunstancias en que se celebró el acto jurídico y a lo que conforme con la noción común, con un criterio general, debe entenderse por tal calidad”. Pues bien, advertido lo anterior ¿constituye la autoría de una fotografía una cualidad esencial en el lenguaje del artículo 1454 CC.? Aunque el asunto sea discutible ${ }^{24}$, la práctica comparada parece mostrar que

${ }^{22}$ Me he detenido sobre esa discusión en DE la Maza Gazmuri, Íñigo, "Comentario", en Revista Chilena de Derecho Privado “Fernando Fueyo Laneri”, 15 (2010), pp. 211-223.

23 "Consorcio de Transportes Trancura Limitada con Romilio Perfecto Tócale Tuna", No identificador Legal Publishing 43283.

${ }^{24} \mathrm{La}$ autenticidad en las obras de arte es un problema espinoso. El problema, como ha sugerido alguna autora es que la autenticidad de una obra es un asunto bastante relativo y volátil [LeQuette-De KervenoaëL, Stéphanie, L'authenticité des oeuvres d'art (París, LGDJ, 2006), p. 252]. Se trata de un asunto relativo porque los medios de determinar la paternidad de una obra no son exactos, y volátil porque, como demuestra el "caso Fragonard", lo que hoy no es atribuido a un autor mañana puede serlo y pasado mañana dejar de serlo. Si esto es correcto, entonces, como ha sugerido Chatelain [invocada por Lequette-De KervenoaëL, S., cit. ibi, p. 333], una obra de arte es naturalmente un bien aleatorio cuya venta implica riesgos para el comprador y el vendedor, por lo tanto, salvo en los supuestos en los que la cualidad se ha incorporado al contrato a través de un deber de garantía o de otra forma, cualquier duda que mantengan las partes en el momento de la celebración del contrato -y este será el caso salvo en aquellas raras ocasiones en las que se disponga de información indubitada respecto a la paternidad o el carácter apócrifo de la obra- determina que ambas estén asumiendo el riesgo de falsedad o autenticidad y que luego no puedan alegar el error. En palabras de Lequette-De KervenoaëL, S., cit. ibi, p. 622: "Elles ont joué: 1'une a gagné, 1'autre a perdu". 
$s^{25}$. Después de todo, probablemente, pocas cosas son más relevantes para determinar el precio de una obra de arte que la identidad de su autor ${ }^{26}$.

Desde luego, no basta que el error sea sustancial para determinar su trascendencia anulatoria, además es necesario que sea excusable; sin embargo, volveré sobre esta característica más adelante ${ }^{27}$. Por ahora me interesa ocuparme de la segunda cuestión que había quedado planteada en este apartado. Lo que quiero considerar ahora, asumiendo provisoriamente que el error posea trascendencia anulatoria es si, satisfaciéndose, además, los requisitos del dolo, la parte afectada puede o no optar por cualquiera de los dos. La respuesta, en mi opinión, debe ser afirmativa. Aunque la doctrina nacional no parece haberse ocupado del tema no existe buenas razones -al menos hasta donde yo alcanzo a ver- para negar lugar a la opción. Existen, por lo demás, antecedentes en Derecho comparado para justificar dicha opción ${ }^{28}$.

${ }^{25}$ Así lo consideró, por ejemplo, el Tribunal Supremo español respecto de un caso en el que el error recaía sobre la autoría de un cuadro de Sorolla. Véase: RJ 1981, 3595. Pte. Excmo. Sr. M. González Alegre y Bernardo. En igual sentido la Corte de Casación francesa respecto de un cuadro de Fragonard. Véase la relación de los hechos en la explicación del caso por FABRE-Magnan, Muriel, De lobligation d'information dans les contrats. Essai d'une théorie (París, LGDJ, 1992), pp. 179-180.

${ }^{26}$ Sobre la importancia de la cualidad para determinar el precio conviene recordar que la Corte Suprema considera precisamente este factor para atribuir el carácter esencial al año de fabricación de los camiones en el caso citado más arriba (véase n...), en los siguientes términos: "En el caso de autos, e incluso abstrayendo al contrato de compraventa de un vehiculo motorizado en general, es manifiesto que el año de fabricación es una cualidad esencial, pues no obstante esta circunstancia no hace que un vehiculo sea lo que es -es decir, no constituye su esencia- ni altera aquello de que se compone-su materia-, evidentemente le da una fisonomía propia, desde que es determinante, ni más ni menos, para la fijación del precio que se paga por él. Este último es, en efecto, un criterio objetivo al que puede recurrirse para calificar la naturaleza del error".

${ }^{27}$ Véase el cap. III, 1, e).

${ }^{28}$ En el derecho español se acepta que, si concurren los requisitos de ambas figuras, la pretensión de anular el contrato pueda ser indistintamente canalizada a través del error o del dolo. Véase: Albaladejo, Manuel, Derecho civil (14a edición, Barcelona, Bosh, 1996), I, p. 611. Se trata de algo así como un "concurso de normas fundamentadoras de una (única) pretensión” (cfr. Pantaleón Prieto, Fernando, s.v. Concurso depretensiones (Derecho Civil), en Enciclopedia Jurídica Básica (Madrid, Civitas, 1995), I, p. 1320, es decir, existe una pretensión (la anulabilidad) que puede fundamentarse en normas jurídicas que disciplinan figuras diversas. Es interesante señalar, además, que según algunos autores, ha existido -y existe- una cierta tendencia de los tribunales a reconducir los supuestos de error inducido al ámbito del error. Rojo Ajuria, L., cit. (n. 11), p. 259, verifica en la jurisprudencia menos reciente una "resistencia a calificar como dolo vicio, cuando se puede anular el contrato por error esencial”. Por su parte, Verda y BeAmonte, J. R., cit. (n. 17), pp. 33-35, señala que, en ocasiones, los tribunales consideran que una inducción a error es determinada por una omisión ilícita que, 
c) Las pretensiones de la demandante. Lo que acabo de sugerir es que la parte podría canalizar sus pretensiones a través de la disciplina del error o la del dolo. Lo que quiero añadir ahora es que al considerar dichas pretensiones se advierte con suficiente claridad la relación que es posible establecer entre error, dolo y deberes precontractuales de información.

Con este objetivo conviene, en primer lugar detenerse acerca de cuáles sean dichas pretensiones. Todo parece indicar que, frente a un caso como el expuesto, las pretensiones pueden ser dos. La primera de ellas consiste en que se prive de efectos al contrato, que se declare su nulidad. La segunda es que se indemnicen los daños y perjuicios.

En el ámbito nacional no parece haber duda que tanto el error como el dolo permiten declarar la nulidad del contrato ${ }^{29}$. Tampoco existen dudas respecto de la acción indemnizatoria que surge al abrigo de la disciplina del dolo in contrabendo $0^{30}$. Lo que no parece haberse discutido es si puede aparejarse una acción indemnizatoria a la demanda de nulidad por error ${ }^{31}$. Esto es, si bajo ciertas circunstancias, quien demanda la nulidad puede, además, solicitar indemnización de perjuicios. La respuesta, en mi opinión, es afirmativa, puede demandar perjuicios bajo las reglas generales del título $35^{\circ}$ del libro

sin embargo, no es calificada como dolo. Este último autor: Error y responsabilidad en el contrato (Valencia, Tirant lo Blanch, 1999), p. 188, advierte además que tanto en la jurisprudencia del Tribunal Supremo como en la de instancia, es posible encontrar una tendencia a reconducir la inducción al error al ámbito del error excusable en detrimento del dolo.

${ }^{29}$ Alguna duda se presenta respecto de si la consecuencia del error obstáculo es la inexistencia, la nulidad absoluta o la nulidad relativa. Véase: VIAL DEL Río, Víctor, Actos jurídicos y personas, v. I, ( $4^{a}$ edición, Santiago, Ediciones Universidad Católica de Chile, 2000), I: Teoría general del acto jurídico, pp. 73-74.

${ }^{30}$ Véase, por ejemplo: León HuRTAdo, Avelino, La voluntad y la capacidad en los actos jurídicos (Santiago, Editorial Jurídica de Chile, 1990), p. 217

${ }^{31}$ Sobre esto conviene hacer una prevención. La indemnización de daños y perjuicios puede ser perseguida tanto por quien padece el error como por quien recibe la declaración de voluntad viciada. En el derecho nacional, LEÓn HURTAdo, A., cit. (n. 30), pp. 181-182, ha considerado esta segunda posibilidad, señalando lo siguiente: "Hemos dicho que el error en la persona produce igual efecto que el error en la substancia o calidad esencial del objeto, y por eso estimamos que la indemnización que se acuerda en el primer caso debería existir también en el segundo, pues tan justo es que se indemnice a la persona con quien erradamente se ha contratado como al contratante de buena fe que tiene la cosa respecto de cuya substancia o calidad esencial yerra el otro contratante. Porque en ambos casos el que acciona de nulidad reconoce su negligencia por no haberse cerciorado, sea de la persona del otro contratante, sea de la substancia o calidad esencial de la cosa”. La solución propuesta se asemeja a la del $\$ 122$ BGB. (sobre el particular puede consultarse Flume, Werner, El negocio jurídico (traducción de Miquel González, J. M. y Gómez Calle, E., Madrid, Fundación Cultural del Notariado, 1998), pp. 503-505. 
IV del Código Civil, siempre y cuando la otra parte haya incurrido en una conducta reprochable, y esto tendrá lugar cuando conocía o debía conocer el error de la otra parte y no se lo comunicó ${ }^{32}$. En un sentido similar parece pronunciarse Claro Solar considerando el caso de error sobre la persona en aquel supuesto en que la persona con quien se contrata sabe del error de la otra y no se lo comunica, señala Claro Solar que: "En este [...] caso habría dolo u ocultamiento culpable de la persona con quien erradamente se contrata; y ella estaría obligada según las reglas generales a indemnizar los daños y perjuicios que hubiese sufrido el que erradamente ha contratado con ella"33. Es cierto que el autor reflexiona en clave de dolo, sin embargo, es posible aplicar el mismo razonamiento en caso de que la persona no conociese el error, pero su ignorancia obedeciese a culpa grave, en cuyo caso no se ve obstáculo para aplicar las reglas generales sobre delitos o cuasidelitos. Esta es, además, la posición mantenida en el Derecho español con reglas suficientemente similares como para que valga la pena considerarlas en este punto ${ }^{34}$.

Si lo que he venido afirmando es correcto, en un caso como el de las fotografías de Baldus, la demandante podría canalizar sus pretensiones de

${ }^{32}$ Así parece haberlo considerado la Corte de Apelaciones de Santiago en "Luis Alberto Muscatt Garrido con Asociación Gremial de Medianos y Santiago”, No identificador Legal Publishing 49274. Se trata de la nulidad por error de un contrato de arrendamiento, en el cual el arrendatario celebra contrato de arrendamiento creyendo que la cosa arrendada tiene la aptitud para ser destinada a local comercial. Por lo demás, en el contrato se había expresado que se le daría dicho uso. Sin embargo, el local no contaba con permiso de edificación y, además, estaba afecto en un $70 \%$ de su superficie a expropiación. En el considerando undécimo de la sentencia del tribunal de alzada se lee: "Que, sin embargo, y siguiendo en esta parte a Arturo Alessandri Besa en su obra La nulidad y la rescisión en el Derecho civil chileno (Santiago, Editorial Jurídica de Chile, 2008), II, pp. 365 ss.): 'es cierto que, entre los efectos de la nulidad, la ley no menciona expresamente la obligación de indemnizar estos perjuicios; pero es un principio general de derecho que todo daño imputable a culpa o dolo de otro debe ser indemnizado por éste, a virtud de lo dispuesto en el artículo 2314 del Código Civil, siendo esta responsabilidad de naturaleza extracontractual. Luego, se ha probado la culpa en la demandada al celebrar un contrato de arrendamiento en los términos que se leen del documento de fojas 1 respecto de un 'local comercial que nunca pudo ser ocupado como tal por no tener permiso de edificación, hecho que estaba en conocimiento del arrendador. Consecuentemente, habiendo desplegado la parte demandada una conducta a lo menos culposa y que produjo daño, éste debe ser reparado. Cabe señalar que el actor no ha indicado en su demanda a qué titulo pretende la indemnización que demanda por responsabilidad contractual o extracontractual, mas por el principio iura novit curia, son los tribunales los encargados de decir el derecho a los hechos planteados por las partes".

${ }^{33}$ Claro Solar, Luis, Explicaciones de Derecho civil chileno y comparado, V: De las obligaciones, II (reimpresión Santiago, Editorial Jurídica de Chile, 1979), p. 179.

${ }^{34}$ Sobre la discusión en el derecho español véase DE LA MAZA GAZMURI, Í., cit. (n. 10), pp. 291-293. 
nulidad del negocio e indemnización de perjuicios a través de la disciplina del error o la del dolo. Ahora bien, resta por ver en qué sentido, se relacionan estas figuras con los dpia. A continuación considero por separado el dolo y el error.

d) La relación entre el dolo y los dpia. ${ }^{35}$. La especie de dolo que aquí interesa es el dolo por omisión o reticencia. Es decir, aquello que se reprocha como doloso no es una actuación positiva, sino una conducta simplemente pasiva consistente en "tolerar consciente, tácitamente, el error ajeno que nosotros mismos no hemos provocado" 36 . Se trata de una especie de dolo que ha sido suficientemente reconocida por la doctrina nacional. Así, por ejemplo, Claro Solar se refiere a "la reticencia o el disimulo" ${ }^{37}$; por su parte León Hurtado señala que "También se puede producir el dolo por omisión; esto es guardando deliberadamente silencio sobre algún hecho o circunstancia que la otra parte necesite conocer para formarse un juicio verdadero de la realidad"38. Finalmente, Alessandri Besa, señala como caso de dolo negativo "el caso del contratante que, debiendo haber dado ciertas informaciones a su contratante y que tenían una importancia decisiva para apreciar las ventajas o desventajas del contrato, guarda silencio al respecto, y debido a este silencio, aquél se celebra" ${ }^{\prime 9}$.

De las tres opiniones, la más sugerente resulta ser la de Alessandri Besa, la razón es que introduce un matiz del cual los otros dos autores prescinden. Señala este autor el caso del contratante que debiendo haber dado ciertas informaciones no lo hace. Y éste es un matiz fundamental, por una sencilla razón: únicamente es posible hablar de dolo por omisión cuando quien, deliberadamente, calla tenía el deber de suministrar información. Para decirlo de otra manera, tratándose de dolo por omisión lo que sucede es que se incumple dolosamente un deber precontractual de información. Consideradas las cosas de esta manera, la primera tarea consiste en determinar si existía un dpia. y, sólo si se llega a una respuesta afirmativa, es posible considerar, como segunda tarea, de qué manera se incumplió. Quizás recordar los hechos del "caso Baldus" contribuya a ilustrar esta idea. En la segunda venta el comprador sabía que la vendedora padecía un error respecto de la autoría de las fotografías, pero no es posible, sin más, considerar que su silencio deliberado

${ }^{35} \mathrm{Me}$ he detenido sobre este tema en mi trabajo: Buena fe, el reverso de la moneda. A propósito del dolo por omisión y el deber precontractual de informar, en Revista Chilena de Derecho Privado "Fernando Fueyo Laneri", 11 (2009), pp. 43-72.

${ }^{36}$ Flume, W., cit. (n. 31), p. 636.

${ }^{37}$ Claro Solar, L., cit. (n. 33), p. 227.

${ }^{38}$ León Hurtado, A., cit. (n. 30), p. 205

${ }^{39}$ Alessandri Besa, Arturo, La nulidad y la rescisión en el Derecho civil chileno (3a ed., actualizada, Santiago, Editorial Jurídica de Chile, 2008), II, p. 63. 
configurase dolo. La operación es más pausada. Resulta necesario, en primer lugar, justificar la existencia del dpia. y luego, si el silencio fue deliberado, entonces se puede afirmar que incumplió dicho deber en forma dolosa.

La relación entre dpia. y dolo por omisión debería resultar clara ahora. Lo que permanece en la duda es cómo determinar la existencia de un dpia.. Me he ocupado de este problema morosamente en otro lugar ${ }^{40}$, por lo mismo no es necesario volver con la misma acuciosidad ahora. Sin embargo, el punto que me interesa hacer aquí es que esa determinación pasa por determinar qué es lo que exige la buena fe a las partes durante la negociación de un contrato y lo que quisiera dejar en claro es que algo que no exige es, bajo cualquier circunstancia, suministrarse toda la información que conozcan y que sea relevante para la otra parte. Por lo mismo, no se puede estar de acuerdo con la Corte de Apelaciones de Santiago cuando señala: "La expectativa es que en esta etapa [la precontractual], los contratantes se den toda la información necesaria para definir los términos del contrato y que esté orientada a ilustrar de la mejor forma a la otra parte, en una actitud de corrección y lealtad" ${ }^{41}$. Lo que sucede es una cuestión distinta, la buena fe constituye un dispositivo que permite al juez ponderar las variables que, en el caso concreto, se encuentran en juego para determinar si se debía o no informar. El mejor ejemplo del cual dispongo para justificar esta afirmación es el tratamiento que prodiga el artículo 4:107 de los Principios Europeos de Derecho de Contratos al dolo. Según dicho precepto ${ }^{42}$ :

i) Cualquiera de las partes puede impugnar el contrato si éste se hubiera concluido en virtud de una representación fraudulenta creada por la otra parte, por medio de sus palabras o de su conducta o como consecuencia de la falta de revelación de información que, de acuerdo con la buena fe y con la equidad, se hubiera debido poner de manifiesto.

${ }^{40}$ DE la Maza Gazmuri, Í., cit. (n. 10).

${ }^{41}$ Véase la nota 8.

${ }^{42}$ Utilizo aquí la traducción de Díez Picazo, L. - Roca Trías, E. - Morales Moreno, A. M, Los principios europeos de derecho de contratos (Madrid, Civitas, 2002), p. 43. El texto en inglés es el siguiente: 1) A party may avoid a contract when it has been led to conclude it by the other party's fraudulent representation, whether by words or conduct, or fraudulent non-disclosure of any information which in accordance with good faith and fair dealing it should have disclosed. (2) A party's representation or non-disclosure is fraudulent if it was intended to deceive. (3) In determining whether good faith and fair dealing required that a party disclose particular information, regard should be had to all the circumstances, including: (a) whether the party had special expertise; (b) the cost to it of acquiring the relevant information; (c) whether the other party could reasonably acquire the information for itself; and (d) the apparent importance of the information to the other party. 
ii) La representación de la parte o la no revelación de información son fraudulentas si se realiza con el intento de engañar.

iii) Para determinar si la buena fe y la lealtad exigen que una parte revele una información concreta deben tomarse en cuenta todas las circunstancias, incluyendo entre ellas:

iv) Si la parte poseía una pericia especial;

v) El costo de adquisición de la información relevante;

vi) Si la otra parte hubiera podido razonablemente adquirir la información por sí misma; $\mathrm{y}$

vii) La aparente importancia que la información tenía para la otra parte.

Si se presta atención al número tres del artículo se advierten dos cosas que resultan de interés aquí. La primera de ellas es que no cualquier silencio configura dolo por omisión, sino, nada más, aquellos en los cuales la buena fe y la lealtad negocial ${ }^{43}$ exigen revelar información. La segunda es que para determinar si se presenta o no esta exigencia "deben tomarse en cuenta todas las circunstancias." En este sentido, la buena fe permite al juez ponderar todas las circunstancias relevantes al momento de decidir si se debía informar o no ${ }^{44}$.

Conviene pensar esto a la luz de los hechos del "caso Baldus", ¿debía informar el fotógrafo a la vendedora acerca de la autoría de las fotografías? De una parte, podría pensarse que no suministrarle la información infringe deberes básicos de lealtad negocial. Sin embargo, el juez podría considerar que la vendedora podría razonablemente haber adquirido la información por sí misma y que, al no hacerlo, aceptó el riesgo de equivocarse ${ }^{45}$. Si el juez limita a esas dos variables el problema lo que, en definitiva, hace al decidir si existió o no dolo por omisión es utilizar la buena fe para decidir cuál de ellas tiene más peso en el caso concreto.

e) La relación entre el error y los dpia. Es posible establecer el vínculo de los dpia. con el error si se deja de considerar al primero, simplemente desde la perspectiva del errans y se toma en consideración la posición de ambas partes. En este sentido, no cualquier error admite dicha vinculación, sino nada más aquellos en que la otra parte conocía o debía conocer el error que padeció la primera.

La relación entre los dpia. y el error se torna particularmente conspicua tratándose de la excusabilidad del error. Si bien resulta ser cierto que los

${ }^{43}$ En su artículo 1:201 (Good Faith and Fair Dealing) disponen que "Cada una de las partes debe actuar de acuerdo con la buena fe y la lealtad" (utilizo la traducción de Díez-Picazo, L. y otros, cit. (n. 42).

${ }^{44}$ Vuelvo sobre la idea de ponderación al final de este trabajo.

${ }^{45}$ Probablemente algo así estimó la Corte de Casación francesa al revocar la sentencia que había acogido la nulidad de dicho contrato por dolo del comprador. 
artículos 1453,1454 y 1455 CC. no contemplan la excusabilidad como requisito del error con trascendencia anulatoria, la doctrina no parece tener problemas para considerarla de esta manera. Así, por ejemplo, Claro Solar, refiriéndose al error obstativo señala que: "Para que el error obstativo sea jurídicamente eficaz, en cuanto a producir el disenso, es necesario que sea excusable, esto es, que no provenga de culpa del que lo alega, o de imprudencia o supina ignorancia suya" ${ }^{\prime \prime 6}$. Por su parte, León Hurtado concibe en los mismos términos la excusabilidad, pero señala que no se limita al error obstáculo, sino a cualquier especie de error vicio ${ }^{47}$. En sentido similar se pronuncian Domínguez Águila ${ }^{48}$ y Martinic Galetovic y Reveco Urzua ${ }^{49}$. Para todos estos autores, la idea es que el Derecho no ampara a quien se comporta de una manera negligente. Se trata de una idea seductora que plasma lo que podría denominarse el "principio de autorresponsabilidad", según el cual, en lo que interesa aquí, bajo ciertas condiciones, se imputan los efectos de una declaración de voluntad a quien la realiza, no obstante la existencia de un error $^{50}$. Ahora bien, la correcta articulación de este principio exige precisar qué es lo que se protege a través de él. Y todo parece indicar que lo protegido es la seguridad del tráfico jurídico, específicamente la confianza de quien recibe la declaración del errans. Como ha sugerido Díez-Picazo: "[...] en el tráfico jurídico, en el mundo de los negocios jurídicos, merece protección la confianza razonable suscitada objetivamente por una situación jurídica: que quien de buena fe realiza un negocio jurídico fundado en la confianza razonable que objetivamente le suscita la una situación de apariencia creada o mantenida por otra persona, debe ser protegido aunque de ello resulte un sacrificio para el interés o para el derecho de otro" $"$.

Si esto es correcto, la función de la excusabilidad como requisito de la trascendencia anulatoria del error no es, por así decirlo, sancionar a quien se comporta sin el debido cuidado en sus negociaciones, sino proteger a quien

${ }^{46}$ Claro Solar, L., cit. (n. 33), p. 154.

${ }^{47}$ LeÓn Hurtado, A., cit. (n. 30), p. 166.

${ }^{48}$ Domínguez Águila, R., El negocio jurídico (Santiago, Editorial Jurídica de Chile, 1976), pp. 84-85.

${ }^{49}$ Martinic Galetovic, D. - Reveco Urzúa , R., Acerca del error, su excusabilidad y otros tópicos, en AA.VV, Estudios de Derecho privado. Libro homenaje al profesor Gonzalo Figueroa Yáñez (Santiago, Editorial Jurídica de Chile, 2008), pp. 139-142

${ }^{50}$ Sobre este principio puede consultarse, en general: Cariota Ferrara, Luigi, El negocio jurídico (traducción al castellano, Madrid, 1956), p. 53. Véase, también: Pietrobon, Vittorino, El error en la doctrina del negocio jurídico (trad. de M. Alonso Pérez, Madrid, Editorial Revista de Derecho Privado, 1971), pp. 268-269.

${ }^{51}$ DíEz-Picazo, L., Fundamentos del Derecho civil patrimonial, I: Introducción, teoría del contrato ( $6^{\mathrm{a}}$ edición, Cizur Menor [Navarra], Thomson Civitas, 2007), pp. 71 72. 
de buena fe confía en la declaración ${ }^{52}$. Al considerar las cosas de esta manera, aparece con toda nitidez que al momento de considerar la excusabilidad o inexcusabilidad resulta necesario un examen comparativo de la conducta de las partes (el errans y el destinatario de la declaración) para determinar quién es más digno de protección ${ }^{53}$.

Así, por ejemplo, en el caso ya citado del minigolf ${ }^{54}$, la demandada consideró que la arrendataria había sido negligente al no haberse cerciorado previamente a la celebración del contrato de las exigencias urbanísticas aplicables al desarrollo del proyecto. Aunque el problema se discutió en sede resolutoria, llevado al lenguaje del error, lo que la demandada señaló es que el error de la demandante consistente en considerar que, jurídicamente, el predio podía destinarse al uso proyectado era inexcusable. Después de todo, le bastaba con acudir a la Municipalidad a preguntarlo y, tratándose de un profesional, sólo su culpa grave explicaría que no hubiese incurrido en este leve esfuerzo. Sin embargo, como ya se ha visto, el tribunal no lo estimó de esa manera. Lo que parece haber considerado es que la arrendadora no podía ignorar dicha información y que la arrendataria podía confiar razonablemente en que si existían limitaciones urbanísticas la arrendadora las conocería y se las informaría. Al no hacerlo, señaló el tribunal, la arrendadora había contravenido las exigencias que formula el principio general de buena fe a los contratantes.

\section{LA DISTRIBUCIÓN DEL RIESGO DE LA DEFECTUOSA INFORMACIÓN Y LA BUENA FE COMO INSTRUMENTO DE PONDERACIÓN}

En la introducción de este trabajo señalé que una vez examinada la relación entre el error y el dolo de una parte y los dpi. de otra, se aprendían dos cosas. La primera de ellas es que el error y el dolo no constituyen exactamente vicios de la voluntad, sino que, algo más que eso. El segundo punto es que, en ocasiones, el principio general de la buena fe opera como un instrumento de ponderación de los diversos intereses que subyacen al Derecho de contratos. Ahora es tiempo de mostrarlo.

${ }^{52}$ Sobre este punto puede confrontarse: Thibierge, Catherine, Nulidad, restituciones y responsabilidad (trad. de Gustavo de Greiff, Bogotá, Universidad Externado de Colombia, 2010), pp. 401-405, quien considera que la inexcusabilidad del error no opera como obstáculo a la trascendencia anulatoria del error, sino que, más bien, justifica la imposición de responsabilidad precontractual por culpa al errans.

${ }^{53}$ Díez-Picazo, L., cit. (n. 51), p. 302 lleva razón entonces cuando señala que "para apreciar la diligencia exigible a la víctima del error, ha de valorarse la conducta de la otra parte".

${ }^{54}$ Véase la nota 9. 
En algún sentido, resulta evidente que el error y el dolo son vicios del consentimiento, después de todo, eso es precisamente lo que dispone el artículo $1451 \mathrm{CC}$. Mi punto, más bien, es que no se puede considerar que proteger el consentimiento sea la única función de estas dos figuras. Cuando se les presta suficiente atención, es posible advertir que, en realidad funcionan como dispositivos para administrar el riesgo de la información defectuosa. Y para hacer esa tarea se sirven de distintos criterios. Uno de ellos, por supuesto, es la protección de la voluntad de las partes, sin embargo, no es el único, ni necesariamente el más importante. Desde mi punto de vista, para que exista error o dolo es necesario que el consentimiento se haya formado incorrectamente, pero no en todos los casos en que el consentimiento se ha formado incorrectamente existe error o dolo.

Así, por ejemplo, parece suceder en los casos en que se considera que el error resulta inexcusable. En ese escenario lo relevante no suele ser si la voluntad se formó correctamente o no, sino, más bien, si existen buenas razones para preferir la posición del destinatario de la declaración por sobre la del errans. Igualmente sucede en el tratamiento que prodigan los PECL. al dolo por omisión, lo determinante no es que la voluntad del deceptus se vea afectada por una comprensión defectuosa de la realidad, sino más bien si quien disponía de la información debía suministrársela.

Cuando se piensan las cosas de esta manera, es posible aceptar, sin mayor fricción, las lúcidas palabras de Díez-Picazo al respecto, según las cuales: "La decisión no recae tanto sobre si el necesario consentimiento se encontraba o no viciado, cuando sobre si es o no justo que es contratante quede o no vinculado y continúe o no estándolo. Para ello, es necesario valorar su propia diligencia y enjuiciar la dignidad que merezca la situación de la otra parte contratante $[. .$.$] más que una monolítica categoría dogmática de vicios del$ consentimiento contractual, que tenga que ser entendida desde un punto de vista lógico, existe lo que puede llamarse un casuismo dogmatizado o, si se prefiere, una tipificación legal de casos de justicia o de injusticia de la vinculación contractual, atendiendo a los hechos ocurridos en el momento de su constitución, de manera que en algunos casos se permite que quien quedó injustamente vinculado por un contrato, pueda desligarse de él y obtener una decisión judicial en virtud de la cual las cosas se restituyan o devuelvan al estado que tenían cuando el contrato se celebró, siempre que ello sea posible" 55 .

Con respecto a la segunda idea, según la cual la buena fe puede considerarse como un mecanismo de ponderación entre los diversos intereses que subyacen

${ }^{55}$ Díez-Picazo, cit. (n. 51), p. 186. 
al Derecho de contratos, la idea, que he desarrollado en otro lugar ${ }^{56}$, es que, al considerar seriamente el Derecho de contratos, se advierte que su diseño articula múltiples intereses y que, en ocasiones estos intereses entran en conflicto. A veces, ese conflicto es resuelto por el legislador ${ }^{57}$, en otras no hay una solución preconfigurada por el legislador y es el juez quien debe resolver la pugna entre los intereses en juego. Así, por ejemplo -y como ya ha quedado dicho-, en el "caso Baldus", es dable sostener que entran en conflicto, de una parte la lealtad contractual y, de otra, la autorresponsabilidad y que, al preguntarse acerca de si el comprador se comportó dolosamente e indagar si la buena fe le exigía informar lo que el juez, en definitiva, hace es ponderar el peso que, en ese caso específico, tenía cada uno de esos dos intereses.

\section{BIBLIOGRAFÍA}

Albaladejo, Manuel, Derecho civil (14a edición, Barcelona, Bosh, 1996), I.

Alessandri Besa, Arturo, La nulidad y la rescisión en el Derecho civil chileno ( $3^{\mathrm{a}}$ edición, actualizada, Santiago, Editorial Jurídica de Chile, 2008), II.

Alonso Pérez, Mariano, La responsabilidad precontractual, en Revista Critica de Derecho Inmobiliario, 485 (1971).

Asúa GonZÁlez, Clara, La culpa “in contrahendo" (Bilbao, Servicio Editorial Universidad del País Vasco, 1989).

Cariota Ferrara, Luigi, El negocio jurídico (traducción al castellano, Madrid, 1956).

Castro y Bravo, Federico de, De nuevo sobre el error en el consentimiento, en Anuario de Derecho Civil, 41 (1988) 2.

Claro Solar, Luis, Explicaciones de Derecho civil chileno y comparado, V: De las obligaciones, II (reimpresión Santiago, Editorial Jurídica de Chile, 1979).

Díez Picazo, L. - Roca Trías, E. - Morales Moreno, A. M. (traductores), Los principios europeos de Derecho de contratos (Madrid, Civitas, 2002).

DíEz-Picazo, L., Fundamentos del Derecho civil patrimonial, I: Introducción, teoría del contrato (6a edición, Cizur Menor [Navarra], Thomson Civitas, 2007).

Ehmann, H. - Sutchet, H., La reforma del BGB. Modernización del Derecho alemán de obligaciones (traducción de C. López Díaz y U. Salas de Sánchez, Bogotá, Universidad Externado de Colombia, 2006).

Fabre-Magnan, Muriel, De lobligation d'information dans les contrats. Essai d'une théorie (Paris, LGDJ, 1992).

Flume, Werner, El negocio jurídico (traducción de Miquel González, J. M. y Gómez Calle, E., Madrid, Fundación Cultural del Notariado, 1998).

${ }^{56}$ Véase de la MAZA Gazmuri, Íñigo., "Casos realmente difíciles: los deberes precontractuales de información y las consideraciones de eficiencia”, en Anuario de Derecho Civil, 63 (2010) 4., pp. 1683-1723.

${ }^{57}$ Así sucede, por ejemplo, con la lesión enorme tratándose de la compraventa de inmuebles. Los intereses que entran en conflicto allí son, de una parte, la autonomía privada y la justicia conmutativa y el que prevalece es la justicia conmutativa. 
García Rubio, María Paz, La responsabilidad precontractual (Madrid, Tecnos, 1991).

Ghestin, Jacques, Traité de droit civil. Les obligations. La formation du contrat (Paris, LGDJ, 1993).

Gómez Calle, Esther, Los deberes precontractuales de información (Madrid, La Ley, 1994).

León Hurtado, Avelino, La voluntad y la capacidad en los actos jurídicos (Santiago, Editorial Jurídica de Chile, 1990).

Lequette-De KervenoaëL, Stéphanie, L'authenticité des oeuvres d'art (París, LGDJ, 2006).

Martinic Galetovic, D. - Reveco Urzúa, R., Acerca del error, su excusabilidad y otros tópicos, en AA.VV, Estudios de Derecho privado. Libro homenaje al profesor Gonzalo Figueroa Yánez (Santiago, Editorial Jurídica de Chile, 2008).

Maza Gazmuri, Íñigo de la, "Comentario" en Revista Chilena de Derecho Privado "Fernando Fueyo Laneri", 13 (2009).

Maza Gazmuri, Ínigo de la, "Comentario", en Revista Chilena de Derecho Privado "Fernando Fueyo Laneri”, 15 (2010).

Maza Gazmuri, Iñigo de la, A propósito del artículo 1861, en AA.VV., Estudios de Derecho civil, V: Jornadas Nacionales de Derecho Civil, Universidad de Concepción, 2009 (Santiago, Abeledo Perrot, Santiago, 2010).

Maza Gazmuri, Iñigo de la, Buena fe, el reverso de la moneda. A propósito del dolo por omisión y el deber precontractual de informar, en Revista Chilena de Derecho Privado "Fernando Fueyo Laneri", 11 (2009).

Maza Gazmuri, Íñigo de la, Casos realmente dificiles: los deberes precontractuales de información y las consideraciones de eficiencia, en Anuario de Derecho Civil, 63 (2010) 4 .

MAZa GAZMURI, Iñigo de la, El suministro de información como técnica de protección de los consumidores: los deberes precontractuales de información, Revista de Derecho de la Universidad Católica del Norte, 17 (Coquimbo, 2010) 2...

Maza Gazmuri, Ínigo de la, Los limites del deber precontractual de información (Cizur Menor [Navarra], Civitas-Thomson Reuters, 2010).

Maza Gazmuri, Íñigo de la, Tipicidad y atipicidad de los deberes precontractuales de información, en Revista de Derecho de la Universidad Católica de Valparaíso, 34 (2010).

Mestre, J. - Fages, B. “Comentario” sobre sentencias judiciales recaídas en materia de obligaciones y contratos especiales, en Revue Trimestrelle de Droit Civil, (2000).

Pantaleón Prieto, Fernando, s.v. Concurso de pretensiones (Derecho Civil), en Enciclopedia Jurídica Básica (Madrid, Civitas, 1995), I.

Pietrobon, Vittorino, El error en la doctrina del negocio jurídico (trad. de M. Alonso Pérez, Madrid, Editorial Revista de Derecho Privado, 1971).

Rojo Ajuria, Luis, El dolo en los contratos (Madrid, Civitas, 1994).

Schmidt, Joanna, La sanction de la faute précontractuelle, en Revue Trimestrelle de Droit Civil, 46 (1974).

Sefton-Green, Ruth, Duties to Inform versus Party Autonomy: Reversing the Paradigm (from Free Consent to Informed Consent)? A Comparative Account of French and English Law, en Howells, G. - Janssen, A. - Schulze, R. (editores), Information Rights and Obligations. A Challenge for Party Autonomy and Transactional Fairness (Ashgate, 2005). 
Thibierge, Catherine, Nulidad, restituciones y responsabilidad (trad. de Gustavo de Greiff, Bogotá, Universidad Externado de Colombia, 2010).

Verda y Beamonte, José Ramón, Algunas reflexiones en torno a la excusabilidady recognoscibilidad del error en los contratos, en Anuario de Derecho Civil, 50 (1997) 3.

VERda y BeAmonte, José Ramón, Error y responsabilidad en el contrato (Valencia, Tirant lo Blanch, 1999).

Verda y BeAmonte, José Ramón, La reticencia en la formación del contrato, en Aranzadi Civil, 22 (1999).

Vial del Río, Víctor, Actos jurídicos y personas (4ª edición, Santiago, Ediciones Universidad Católica de Chile, 2000), I: Teoría general del acto jurídico. 
